Pacific Journal of Mathematic 


\title{
FIXED POINTS IN PARTIALLY ORDERED SETS
}

\section{R. E. SMITHSON}

\begin{abstract}
In the first section of this paper a converse of a fixed point theorem for increasing functions on partially ordered sets is obtained. In the second part of the paper some results on common fixed points for commuting families of functions are extended to multifunctions and some known results are obtained as corollaries.
\end{abstract}

The results referred to above are in [1], [2], [5], and [6]. In [5] Smithson extended a theorem of Abian and Brown [1] to multifunctions, and by using the results of Davis [2] obtained a characterization of complete lattices in terms of fixed points of multifunctions as a corollary. In the first part of this note, the converse of Theorem 1.1 of [5] is proved and thus a characterization of certain partially ordered sets in terms of the fixed point property is obtained. This theorem extends a result of Davis [2]. In the second part some theorems for commuting functions and commuting multifunctions are obtained. These results extend a theorem of Tarski [6].

In the following $(X, \leqq)$ is a nonempty set with a partial order $\leqq$. A subset $C$ of $X$ is called a chain in case it is totally ordered. Least upper bounds are defined in the usual way and $x<y$ means $x \leqq y$ and $x \neq y$. A multifunction $F: X \rightarrow X$ is a point to set correspondence. (i.e., $F(X)$ is a nonempty subset of $X$ for each $x \in X$.) The term function shall mean a single-valued function. We shall denote a multifunction by an upper case letter, $F, G$ etc., and a function by a lower case letter. A function $f: X \rightarrow X$ is increasing in case $x \leqq y, x, y \in X$, implies that $f(x) \leqq f(y)$. Let $F: X \rightarrow X$ be a multifunction on $X$ into $X$. Then we use the following two conditions from [5] (Condition II was designated III in [5]).

I. If $x_{1} \leqq x_{2}, x_{1}, x_{2} \in X$, and if $y_{1} \in F\left(x_{1}\right)$, then there is a $y_{2} \in F\left(x_{2}\right)$ such that $y_{1} \leqq y_{2}$.

II. Let $C$ be a chain in $X$ and suppose there is an increasing function $f: C \rightarrow X$ such that $f(x) \in F(x)$ for all $x \in C$. If $x_{0}=\operatorname{lub} C$, then there exists a $y_{0} \in F\left(x_{0}\right)$ such that $f(x) \leqq y_{0}$ for all $x \in C$.

Note that an increasing single-valued function may be considered a multifunction and satisfies both Conditions I and II.

Finally if $f: X \rightarrow X$ is a function, a fixed point of $f$ is a point $x \in X$ such that $f(x)=x$ and if $F$ is a multifunction, then $x$ is a fixed point in case $x \in F(x)$. 
1. The converse of a fixed point theorem. In [5] the following extension of a result of Abian and Brown [1] was proved.

THEOREM A. Suppose that each nonempty chain in $X$ has a least upper bound and suppose that $F: X \rightarrow X$ is a multifunction that satisfies $I$ and $I I$. If there is an $e \in X$ and a point $y \in F(e)$ such that $e \leqq y$, then $F$ has a fixed point.

First note that we only needed to assume that each chain which contains $e$ has a least upper bound. Next, since increasing functions satisfy Conditions I and II, we state and prove the converse of Theorem A for functions and obtain as a corollary a characterization of the fixed point property for a class of multifunctions on a partially ordered set. Theorem 1.2 is also an extension of a result of Davis [2]. Lemma 1.1. below is given as an exercise on page 68 of [4] and the proof is omitted.

LEMma 1.1. Every nonempty chain in a partially ordered set contains a well ordered cofinal subset.

We also need the condition used by Wolk in [7].

D. If $a, b$ are upper bounds of a totally ordered subset $A$ of the partially ordered set $X$, then there is an upper bound $d$ for $A$ such that $d \leqq a$ and $d \leqq b$.

THEOREM 1.2. Suppose that $(X, \leqq)$ is a partially ordered set which satisfies condition $D$. Let $e \in X$ and suppose that there is a chain $C$ in $X$ which contains $e$ and which does not have a least upper bound in $X$. Then there exists an increasing function $f: X \rightarrow X$ such that $e \leqq f(e)$ and $f(x) \neq x$ for all $x \in X$.

Proof. By applying Lemma 1.1 we obtain a well ordered cofinal subset $W$ of $C$ which contains $e$ as a smallest element. Further, since $C$ does not have a least upper bound in $X$ neither does $W$. We have two main cases to consider. First assume that there is an upper bound of $W$ in $X$, and set $A=\{x \in X: x$ is an upper bound of $W\}$. Then apply the Hausdorff maximal principle to obtain a maximal chain in $A$, and from this maximal chain we obtain a set $B$, by applying Lemma 1.1 to the dual order, such that if $x$ is in the chain, there is a $b \in B$ with $b \leqq x$, and such that each nonempty subset of $B$ contains a largest element. Then by Condition $\mathrm{D}$ no element of $A$ is a lower bound of $B$, and we define $\mathrm{f}: X \rightarrow X$ as follows. First suppose that $x \notin A$ and set $W(x)=\{w \in W: w \geqq x\} \neq \varnothing$. Then set 
$f(x)=\min W(x)$. Next suppose that $x \in A$. Then the set $B(x)=$ $\{b \in B: x \not \leq b\} \neq \varnothing$, and we set $f(x)=\max B(x)$. To see that $f$ is increasing suppose that $x_{1} \leqq x_{2}$. If $x_{1} \in A$, then $x_{2} \in A$ and $B\left(x_{1}\right) \subset B\left(x_{2}\right)$; hence $f\left(x_{1}\right) \leqq f\left(x_{2}\right)$. If neither $x_{1}, x_{2}$ are in $A$, then $W\left(x_{1}\right) \supset W\left(x_{2}\right)$ which implies that $f\left(x_{1}\right) \leqq f\left(x_{2}\right)$. Finally if $x_{1} \notin A$ and $x_{2} \in A$ then $f\left(x_{1}\right) \in W$, and $f\left(x_{2}\right) \in B$ which again implies that $f\left(x_{1}\right) \leqq f\left(x_{2}\right)$. To see that $f$ has no fixed point first observe that $f(X) \subset W \cup B$ and hence, $f(x) \neq x$ for all $x \notin W \cup B$. If $x \in W$, then $f(x)=\min \{w \in W: x<w\}$ and if $x \in B$, then $f(x)=\max \{b \in B: b<x\}$. In any case $f(x) \neq x$. Finally note that $e \leqq f(e)$.

To complete the proof suppose that $W$ has no upper bound. Then for $x \in X$, set $W(x)=\{w \in W: w \geqq x\}$, and set $f(x)=\min W(x)$. The verification that $e \leqq f(e), f$ is increasing and that $f$ has no fixed point is analogous to the above case.

CoRollary 1.3. Let $e \in X$ and let $\mathscr{F}$ be the set of multifunctions on $X$ which satisfies Conditions $I$ and II. Further, suppose that for each $F \in \mathscr{F}$ there is $a y \in F(e)$ such that $e \leqq y$. Then every multifunction in $\mathscr{F}$ has a fixed point if and only if each chain in $X$ which contains $e$ has a least upper bound in $X$.

2. Commuting families. In this section we obtain an analog of Theorem A for commuting families of functions, and we extend a theorem of Tarski's [6] to commuting families of multifunctions where a family of functions is commuting in case $f, g \in \mathscr{F}$ implies that $f \circ g=g \circ f$.

Theorem 2.1 below is a version of a theorem of DeMarr [3].

Theorem 2.1. Let $e \in X$ and let $\mathscr{F}$ be a commuting family of increasing functions on $X$ into $X$ such that $e \leqq f(e)$ for all $f \in \mathscr{F}$. If each chain in $X$ which contains e has a least upper bound in $X$, then there is a point $x \in X$ such that $f(x)=x$ for all $f \in \mathscr{F}$.

Proof. Let $\mathscr{S}$ be the set of all chains in $X$ which contain $e$ and which satisfy: If $x \in C \in \mathscr{S}$, then $x \leqq f(x)$ for all $f \in \mathscr{F}$. By Zorn's lemma there exists a maximal element $C_{0}$ in $\mathscr{S}$. Let $x_{0}=\operatorname{lub} C_{0}\left(x_{0}\right.$ exists since $C_{0}$ is a chain and $e \in C_{0}$ ). First we shall show that $x_{0} \in C_{0}$. For let $f \in \mathscr{F}$ and let $x \in C_{0}$. Then $x \leqq x_{0}$ and therefore $x \leqq f(x) \leqq f\left(x_{0}\right)$. Hence, $f\left(x_{0}\right)$ is an upper bound for $C_{0}$ and thus $x_{0} \leqq f\left(x_{0}\right)$. Next suppose that $x_{0} \neq f\left(x_{0}\right)$ for some $f \in \mathscr{F}$. Then we shall show that $C_{0} \cup\left\{f\left(x_{0}\right)\right\} \in \mathscr{S}$. For this let $g \in \mathscr{F}$. Then $x_{0} \leqq g\left(x_{0}\right)$ and $f\left(x_{0}\right) \leqq$ $g\left(f\left(x_{0}\right)\right)$. Hence, $C_{0} \cup\left\{\left(f\left(x_{0}\right)\right\} \in \mathscr{S}\right.$ which contradicts the maximality of $C_{0}$. Hence, $f\left(x_{n}\right)=x_{0}$ for all $f \in \mathscr{F}$. 
A family $\mathscr{F}$ of multifunctions is commuting in case $F \circ G=G \circ F$ for all $F, G \in \mathscr{F}$ where $F \circ G(x)=F(G(x))=\bigcup\{F(y): y \in G(x)\}$.

Proposition 2.2. Let $\mathscr{F}$ be a family of commuting multifunctions on $X$ into $X$ such that each member of $\mathscr{F}$ satisfies $I$. Suppose that $l u b F(x) \in F(x)$ for all $F \in \mathscr{F}$ and $x \in X$. Then for $F \in \mathscr{F}$ define $f(x)=l u b F(x)$ for all $x \in X$. If $\mathscr{F}_{0}$ is the collection of such functions, then $\mathscr{F}_{0}$ is a commuting family and each member of $\mathscr{F}_{0}$ is increasing.

Proof. Let $f, g \in \mathscr{F}_{0}$ where $f(x)=\operatorname{lub} F(x)$ and $g(x)=\operatorname{lub} G(x)$ for all $x \in X$. Then $f(g(x)) \in F(G(x))=G(F(x))$. Thus there is a $y \in F(x)$ such that $f(g(x)) \in G(y)$. Further, $y \leqq f(x)=\operatorname{lub} F(x)$, and so by $I$ there exists a $z \in G(f(x))$ such that $f(g(x)) \leqq z$. Therefore $f(g(x)) \leqq$ $g(f(x))$, and we also get $g(f(x)) \leqq f(g(x))$ by a similar argument. Thus $f \circ g=g \circ f$. Finally, if $x_{1} \leqq x_{2}$, Condition I implies that lub $F\left(x_{1}\right) \leqq$ lub $F\left(x_{2}\right)$ and hence, each $f \in \mathscr{F}_{0}$ is increasing.

Before giving the next theorem we examine a simple example which shows that Condition I was needed in Proposition 2.2.

ExAmple. Let $X=[0,1]$ and define two multifunctions $F$ and $G$ as follows: Let $G(x)=X$ for all $x \in X$ and $F(x)=X$ for $0 \leqq x<1$ and $F(1)=0$. Then $F \circ G=G \circ F$ but if $f(x)=\operatorname{lub} F(x)$ and $g(x)=$ lub $G(x)$, then $f(g(x))=0$ and $g(f(x))=1$ for all $x \in X$,

THEOREM 2.3. Let $e \in X$ and suppose each chain containing e has a lub in $X$. Let $\mathscr{F}$ be a commuting collection of multifunctions on $X$ into $X$ such that there exists $y \in F(e)$ with $e \leqq y$ for each $F \in \mathscr{F}$. If each $F \in \mathscr{F}$ satisfies Condition $I$, and if $l u b F(x) \in F(x)$ for each $F \in \mathscr{F}$ and for all $x \in X$, then there exists an $x \in X$ such that $x \in F(x)$ for all $F \in \mathscr{F}$.

\section{Proof. Apply Proposition 2.2 and Theorem 2.1.}

As a corollary we obtain an extension of a theorem of Tarski [6].

CoRollary 2.4. Let $X$ be a complete lattice and let $\mathscr{F}$ be a commuting family of multifunctions on $X$. If each $F \in \mathscr{F}$ satisfies Condition $I$ and if $l u b F(x) \in F(x)$ for each $F \in \mathscr{F}$ and $x \in X$, then there is a common fixed point for the members of $\mathscr{F}$.

\section{REFERENCES}

1. S. Abian and A. B. Brown, A theorem on partially ordered sets with applications to fixed point theorems, Canadian J. Math., 13 (1961), 78-82.

2. A. C. Davis, A characterization of complete lattices, Pacific J. Math., 5 (1955), 311-319. 
3. R. DeMarr, Common fixed points for isotone mappings, Colloquium Math., 13 (1964), 45-48.

4. P. R. Halmos, Naive Set Theory, Princeton, 1960.

5. R. E. Smithson, Fixed points of order preserving multifunctions, Proc. Amer. Math. Soc,. 28 (1971), 304-310.

6. A. Tarski, A lattice-theoretical fixpoint theorem and its applications, Pacific J. Math., 5 (1955), 285-309.

7. E. S. Wolk, Dedekind completeness and a fixed point theorem, Canad. J. Math., 9 (1957), 400-405.

Received November 18, 1971 and in revised form April 7, 1972. Presented to the American Mathematical Society in Las Vegas, Nevada, January 17, 1972.

UNIVERSITY OF WYOMING 



\section{PACIFIC JOURNAL OF MATHEMATICS}

EDITORS

\author{
H. SAMELSON \\ Stanford University \\ Stanford, California 94305 \\ C. R. HOBBY \\ University of Washington \\ Seattle, Washington 98105
}

\author{
J. DUGUNDJI \\ Department of Mathematics \\ University of Southern California \\ Los Angeles, California 90007 \\ RICHARD ARENS \\ University of California \\ Los Angeles, California 90024
}

\section{ASSOCIATE EDITORS}

E. F. BECKENBACH

B. H. NeUManN

F. WOLF

K. YosHIDA

\section{SUPPORTING INSTITUTIONS}

UNIVERSITY OF BRITISH COLUMBIA

CALIFORNIA INSTITUTE OF TECHNOLOGY

UNIVERSITY OF CALIFORNIA

MONTANA STATE UNIVERSITY

UNIVERSITY OF NEVADA

NEW MEXICO STATE UNIVERSITY

OREGON STATE UNIVERSITY

UNIVERSITY OF OREGON

OSAKA UNIVERSITY
UNIVERSITY OF SOUTHERN CALIFORNIA

STANFORD UNIVERSITY

UNIVERSITY OF TOKYO

UNIVERSITY OF UTAH

WASHINGTON STATE UNIVERSITY UNIVERSITY OF WASHINGTON

AMERICAN MATHEMATICAL SOCIETY NAVAL WEAPONS CENTER 


\section{Pacific Journal of Mathematics}

\section{Vol. 45, No. $1 \quad$ September, 1973}

William George Bade, Complementation problems for the Baire classes .......... 1

Ian Douglas Brown, Representation of finitely generated nilpotent groups ........ 13

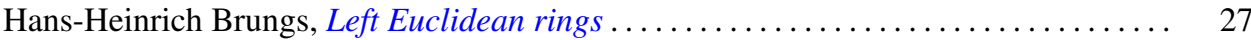

Victor P. Camillo and John Cozzens, A theorem on Noetherian hereditary rings ..... 35

James Cecil Cantrell, Codimension one embeddings of manifolds with locally flat

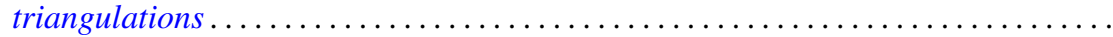

L. Carlitz, Enumeration of up-down permutations by number of rises . . . . . . . . . .

Thomas Ashland Chapman, Surgery and handle straightening in Hilbert cube

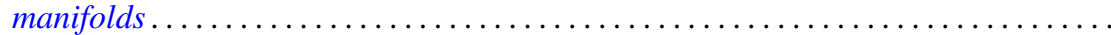

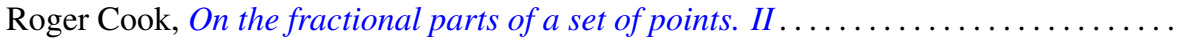

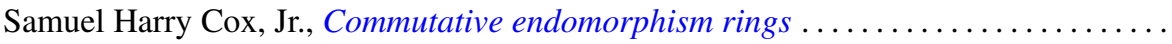

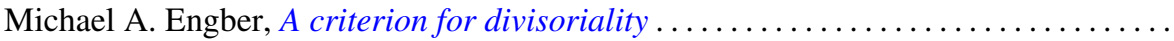

Carl Clifton Faith, When are proper cyclics injective . . . . . . . . . . . . . . 97

David Finkel, Local control and factorization of the focal subgroup . . . . . . . . . 113

Theodore William Gamelin and John Brady Garnett, Bounded approximation by

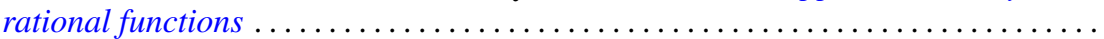

Kazimierz Goebel, On the minimal displacement of points under Lipschitzian

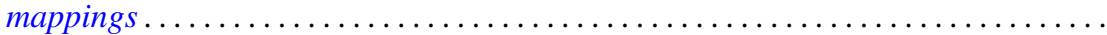

Frederick Paul Greenleaf and Martin Allen Moskowitz, Cyclic vectors for representations associated with positive definite measures: nonseparable

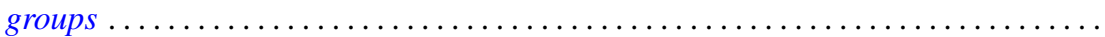

Thomas Guy Hallam and Nelson Onuchic, Asymptotic relations between perturbed linear systems of ordinary differential equations .

David Kent Harrison and Hoyt D. Warner, Infinite primes of fields and completions. .

James Michael Hornell, Divisorial complete intersections . ......

Jan W. Jaworowski, Equivariant extensions of maps ..............

John Jobe, Dendrites, dimension, and the inverse arc function .. .

Gerald William Johnson and David Lee Skoug, Feynman integrals of non-factorable

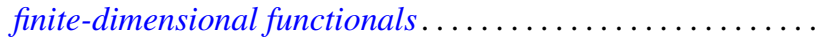

Dong S. Kim, A boundary for the algebras of bounded holomorphic functions ...... 269

Abel Klein, Renormalized products of the generalized free field and its derivatives ... 275

Joseph Michael Lambert, Simultaneous approximation and interpolation in $L_{1}$ and

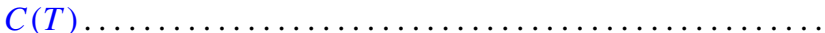

Kelly Denis McKennon, Multipliers of type $(p, p)$ and multipliers of the group

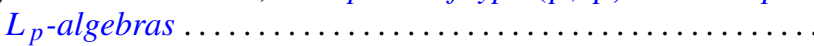

William Charles Nemitz and Thomas Paul Whaley, Varieties of implicative

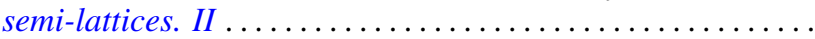

Donald Steven Passman, Some isolated subsets of infinite solvable

Norma Mary Piacun and Li Pi Su, Wallman compactifications on E-completely

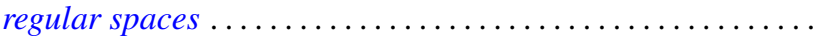

Jack Ray Porter and Charles I. Votaw, $S(\alpha)$ spaces and regular Hausdorff extensions....

Gary Sampson, Two-sided $L_{p}$ estimates of convolution transforms .

Ralph Edwin Showalter, Equations with operators forming a rig
Raymond Earl Smithson, Fixed points in partially ordered sets .

Victor Snaith and John James Ucci, Three remarks on symmetric products and

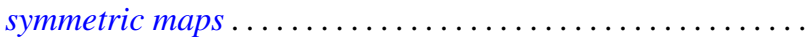

